\title{
Differences in anthropometric characteristics between young soccer players (U19) members of the best soccer clubs in Montenegro, Bosnia and Herzegovina, and Kosovo
}

\author{
Gardasevic J. ${ }^{\mathrm{ABCDE}}$, Bjelica D. ${ }^{\mathrm{ABCD}}$, Vasiljevic I. ${ }^{\mathrm{BDE}}$ \\ Faculty for Sport and Physical Education, University of Montenegro, Montenegro
}

Authors' contribution: A - Study design; B - Data collection; C - Statistical analysis; D - Manuscript Preparation; E Funds collection.

\begin{abstract}
Purpose: $\quad$ The aim of this research was to determine the differences between the young soccer players (U19) in terms of anthropometric characteristics and body composition. We considered players of three the most successful clubs in three countries of the southern region of the Balkan Peninsula.

Material: $\quad$ The first sub-sample of the subjects was consisted of 17 players of OFC Titograd from Montenegro of the average age 17.12 \pm .69. The second sub-sample was consisted of 14 players of FC Siroki Brijeg from Bosnia and Herzegovina of the average age of $18.14 \pm .86$. The last sub-sample of the examinees was consisted

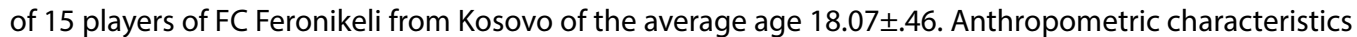
in the body composition were evaluated by a battery of 11 variables. The significance of the differences between the young soccer players in the anthropometric characteristics and variables for assessing body composition were determined by ANOVA and LSD Post Hoc test.

Results: $\quad$ The young soccer players of the three mentioned clubs have statistically significant differences by the two variables that estimate the upper leg skinfold and fat percentage. The young soccer players of OFC Titograd are significantly better in variable upper leg skinfold than other players. The young soccer players of FC Feronikeli are significantly better in variable fat percentage than players of OFC Titograd.

Conclusions: $\quad$ The results can be useful for coaches of other clubs for making a comparison of their soccer players with the young soccer players in this research.

Keywords: $\quad$ anthropometric characteristics, body composition, young soccer players, Balkan Peninsula.
\end{abstract}

\section{Introduction}

Soccer is the most popular sport in the world, with up to 270 million participants [1]. A soccer game is said to be the most important secondary thing in the world. It gathers huge masses at stadiums and in front of TVs [2]. It is a highly dynamic and fast team game which, with its richness of movement, falls under category of polystructural sports games. Soccer is a sport characterized by numerous and various complex and dynamic kinesiological activities which are then characterized by either cyclical or acyclical movement [3]. Ability to run more for players or at the other hand distance covered during each full time competition significantly influenced by aerobic capacity and endurance performance [4]. In soccer, top score can be achieved only under conditions of well-programmed training process. High quality management of the training process depends on the knowing of the structure of certain anthropological capabilities and player's characteristics, as well as their development. Various researches are to be done in order to establish certain principles and norms for the transformational processes of the anthropological characteristics important for soccer. However, in many places much more time is spent on increasing the physical fitness of athletes without taking into consideration the assessment of their body composition and their nutritional status [5]. Findings regarding anthropometric characteristics and body composition are of crucial importance for complex sports games such as soccer. The anthropometric space is defined by the longitudinal

(c) Gardasevic J., Bjelica D., Vasiljevic I., 2020

doi:10.15561/18189172.2020.0103 dimension of the skeleton, the transversal dimensionality of the skeleton and the mass and volume of the body. The purpose of knowing anthropometric characteristics is to improve skills in many sports [6]. The anthropometric status of top level athletes is relatively homogeneous, depending on the sport, and it can be defined as a model of athletic achievement. Research on anthropometric characteristics and body composition among athletes of different sports indicates that athletes of different sports have their own specific characteristics. This is mostly due to the reason that absolute size contributes a significant percentage of total variance associated with athletic success [7]. Muscle mass improves performance in activities that require muscular strength and endurance, but also in those that require enviable aerobic ability [8, $9,10]$. The athlete's belonging to a certain sports branch gives to an athlete certain anthropometric characteristics and body compositions. It gives him the advantage of dealing with this sport in relation to others.

Today, soccer is certainly the number one sport in the world for its rating and popularity, and the same applies to the countries of the southern region of the Balkan Peninsula. These are the countries of the former Yugoslavia where soccer was the number one sport, and untill today it has maintained its primacy in Montenegro, in Bosnia and Herzegovina, and in Kosovo. In all these countries a lot of work is being done to develop young soccer players. They all want to develop soccer players and sell them to the rich clubs in Europe. Mostly in this way soccer clubs in these countries provide their annual budgets. The three clubs that are at the top of the youth soccer of their countries 
are Soccer Club Titograd (hereinafter OFC Titograd) from Montenegro, Soccer Club Siroki Brijeg (hereinafter FC Siroki Brijeg) from Bosnia and Herzegovina and Soccer Club Feronikeli (hereinafter FC Feronikeli) from Kosovo. It became interesting for researchers to determine the models of anthropometric characteristics and body composition of these soccer players, as well as to determine the differences among them.

The aim of this research was to analyze the differences in some anthropometric characteristics and body composition among young soccer players (U19), players of OFC Titograd from Montenegro, FC Siroki Brijeg from Bosnia and Herzegovina and FC Feronikeli from Kosovo.

\section{Material and Methods}

Participants: A sample of the subjects consists of a total of 46 young soccer players from three different countries, divided into three sub-samples. The first subsample of the subjects was consisted of 17 players of OFC Titograd from Montenegro of the average age 17.12 \pm .69 , the second sub-sample was consisted of 14 players of FC Siroki Brijeg from Bosnia and Herzegovina of the average age of $18.14 \pm .86$, and the last sub-sample of the examinees was consisted of 15 players of FC Feronikeli from Kosovo of the average age $18.07 \pm .46$. The soccer players were tested immediately after the season 2018/19 ended.

Procedure: Anthropometric research has been carried out with respect to the basic rules and principles related to the selection of measuring instruments and measurement techniques standardized in accordance with the International Biological Program guidelines. For the purpose of this study, eight (8) anthropometric measures have been taken: body height, body weight, triceps skinfold, biceps skinfold, skinfold of the back, abdominal skinfold, upper leg skinfold and lower leg skinfold, and three (3) body composition assessment variables: body mass index, fat percentage and muscle mass. Anthropometer, caliper, and measuring tape were used for anthropometric measurements. To evaluate the body composition, Tanita body fat scale - model BC-418MA, was used. The principle of this scale is based on indirect measurement of the body composition; a safe electrical signal is transmitted through the body via electrodes located in the standalone unit. The Tanita Scale, thanks to its athletics mode, enables athletes to closely monitor their body weight, health condition and form with all relevant parameters.

Statistical analysis: The data obtained through the research were processed by descriptive and comparative statistical procedures. For each variable, central and dispersion parameters have been processed. The significance of the differences between the players of the three successful soccer clubs in the anthropometric characteristics and variables for assessing body composition was determined by ANOVA and LSD Post Hoc tests, with statistical significance of $p<0.05$.

\section{Results}

The variables for assessing anthropometric characteristics and body composition of young soccer players and ANOVA to identify significant differences between them are shown in Table 1.

ANOVA test (Table1) found that the young soccer players of the three mentioned clubs have statistically significant differences by the two variables that estimate the upper leg skinfold $(\mathrm{F}=4.68)$ and fat percentage $(\mathrm{F}=4.39)$. LSD post hoc test confirmed the significant differences of upper leg skinfold and fat percentage among the soccer players of these three clubs (Table 2).

The LSD Post Hoc test showed significant differences in upper leg skinfold the young soccer players of the three clubs (Table 2). The OFC Titograd players had significantly lowest upper leg skinfold than the players of FC Siroki Brijeg $(p<0.01)$ and FC Feronikeli $(p<0.05)$. The LSD Post Hoc test also showed significant differences in fat percentage the young soccer players of the two clubs (Table 2). The FC Feronikeli players had significantly lowest fat percentage than the players of OFC Titograd $(\mathrm{p}<0.01)$.

The significant differences of upper leg skinfold and fat percentage among the young soccer players of these clubs are shown in Figure 1.

Table 1. Descriptive data and ANOVA of 46 young soccer players, members of the three clubs

\begin{tabular}{llllll}
\hline Variables & OFC Titograd & \multicolumn{2}{l}{ FC Siroki Brijeg } & FC Feronikeli & \multicolumn{2}{c}{ ANOVA } \\
& Mean \pm Standard Deviation & & F & Sig. \\
\hline body height $(\mathrm{cm})$ & $180.60 \pm 5.38$ & $181.55 \pm 5.32$ & $178.57 \pm 7.19$ & .94 & .39 \\
body weight $(\mathrm{kg})$ & $71.70 \pm 4.99$ & $73.59 \pm 8.79$ & $69.41 \pm 7.37$ & 1.26 & .29 \\
triceps skinfold $(\mathrm{mm})$ & $6.26 \pm 1.83$ & $8.19 \pm 2.45$ & $8.04 \pm 3.71$ & 2.45 & .09 \\
biceps skinfold $(\mathrm{mm})$ & $4.79 \pm 1.34$ & $4.39 \pm .67$ & $5.11 \pm 1.39$ & 1.29 & .29 \\
skinfold of the back $(\mathrm{mm})$ & $9.01 \pm 1.43$ & $8.65 \pm 1.34$ & $8.67 \pm 1.66$ & .29 & .75 \\
abdominal skinfold $(\mathrm{mm})$ & $10.81 \pm 4.63$ & $9.21 \pm 2.52$ & $8.69 \pm 3.77$ & 1.3 & .27 \\
upper leg skinfold $(\mathrm{mm})$ & $7.88 \pm 2.29$ & $12.18 \pm 4.28$ & $11.13 \pm 5.41$ & 4.68 & .01 \\
lower leg skinfold $(\mathrm{mm})$ & $6.54 \pm 2.29$ & $6.56 \pm 1.96$ & $6.34 \pm 2.73$ & .04 & .96 \\
body mass index $\left(\mathrm{kg} / \mathrm{m}^{2}\right)$ & $21.95 \pm 1.22$ & $22.16 \pm 1.67$ & $21.72 \pm 1.61$ & .32 & .73 \\
fat percentage $(\%)$ & $10.41 \pm 3.42$ & $8.37 \pm 3.65$ & $7.17 \pm 2.13$ & 4.39 & .02 \\
muscle mass $(\mathrm{kg})$ & $36.35 \pm 2.89$ & $37.92 \pm 3.61$ & $36.47 \pm 3.76$ & .96 & .39 \\
\hline
\end{tabular}


Table 2. LSD Post Hoc tests

\begin{tabular}{llllll}
\hline Dependent Variable & club & & Mean Differ. & Std. E & Sig. \\
\hline \multirow{3}{*}{ upper leg skinfold } & \multirow{2}{*}{ OFC Titograd } & FC Siroki Brijeg & $-4.30^{* *}$ & 1.49 & .006 \\
& & FC Feronikeli & $-3.25^{*}$ & 1.46 & .032 \\
& \multirow{3}{*}{ FC Siroki Brijeg } & OFC Titograd & $4.30^{*}$ & 1.49 & .006 \\
& & FC Feronikeli & 1.05 & 1.53 & .496 \\
fat percentage & OFC Titograd & FC Siroki Brijeg & 2.04 & 1.13 & .079 \\
& & FC Feronikeli & $3.24^{* *}$ & 1.11 & .006 \\
& \multirow{2}{*}{ FC Siroki Brijeg } & OFC Titograd & -2.04 & 1.13 & .079 \\
& & FC Feronikeli & 1.20 & 1.17 & .308 \\
\hline
\end{tabular}

Legend: ${ }^{*}-p<0.05 ; * *-p<0.01$
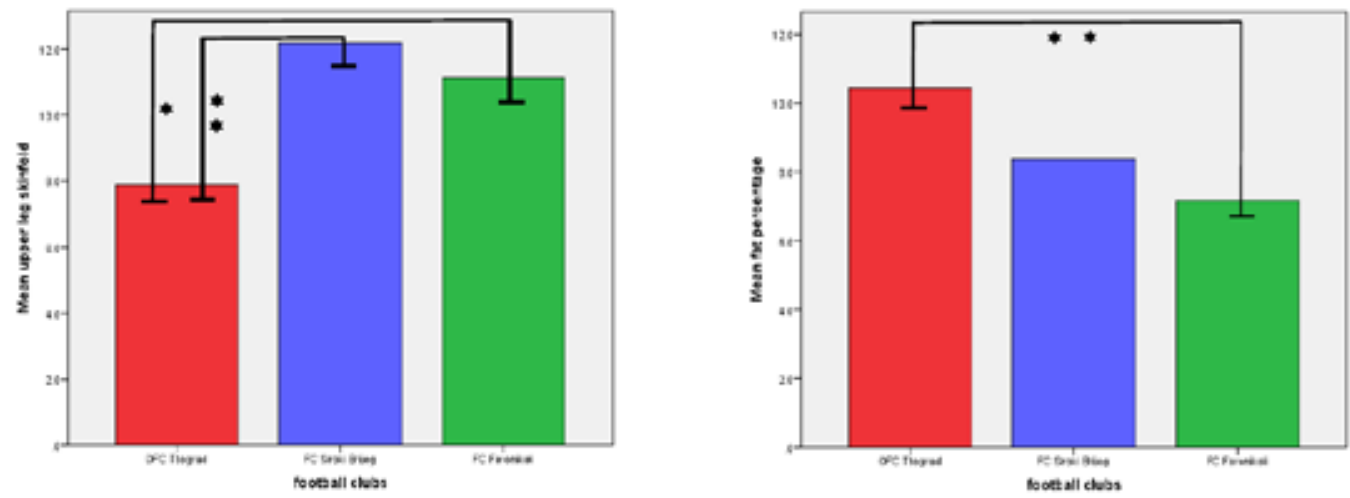

Figure 1. Statistically significant differences between young football players of football clubs in two variables - upper leg skinfold and fat percentage $\left({ }^{*} p<.05 ;{ }^{* *} p<.01\right)$

\section{Discussion}

Considering the basic descriptive statistical parameters, it can be concluded that we have examined selected players. It can be noticed that the soccer players of these three clubs are of the approximately similar mean values of the variables analyzed. This is not surprising as these are the top three clubs in Montenegro, Bosnia and Herzegovina, and Kosovo, i.e. a concentration of the best players. The ANOVA showed that the young soccer players of the three mentioned clubs have statistically significant differences by the two variables. The first is upper leg skinfold and the second is fat percentage. The LSD Post Hoc test showed that the players of OFC Titograd have significantly lower values of upper leg skinfold than the players of FC Siroki Brijeg and FC Feronikeli. Soccer players of OFC Titograd have shown statistically better values because a smaller number means a better result when the disrupting factor of subcutaneous fat on playing soccer is considered. The second variable in which a statistically significant difference has been found is a variable that estimates body composition, fat percentage. The LSD Post Hoc test shows that the soccer players of FC Feronikeli had the significantly lowest fat percentage compared to the soccer players of OFC Titograd $(p<0.01)$, but no significant differences compared to the soccer players of FC Siroki Brijeg. Moreover, it is wellknown that low fat percentage is desirable for high physical performance in all sports. Although, not every body composition characteristic is expected to play a role in optimal performance in professional soccer. Lower levels of body fat (that are specific to each player) are desirable for optimal performance as body mass must be moved against gravity [11]. In other words, by achieving optimal levels of body fat and fat-free mass, the player can minimize the negative effects of excess body fat without sacrificing skill.

However, despite the significant differences all the soccer players had a lower percentage of fat and these results. This was expected, because many of the previous research recognized soccer as a predominantly aerobic sport [12]. Furthermore, it is very important to soccer players to have a determined body fat percentage in order to perform well enough and achieve their full playing potential. The fat percentage soccer players of English Premier League vary from 9.9 percent to 12.9 percent, depending on the position [13], in Japan 8.5-13.7\% [14], in Zimbabwe 9.2-11.2\% [15]. However, these are just guidelines and the players would work together with their coaches to determine the individual body fat percentage to enhance their physical abilities and their health. The importance of body composition in sport performance is a primary concern in creating athlete profiles as well as conditioning programs throughout a season at all levels of competition [16]. Those describing anthropometric characteristics and body composition of athletes and detecting possible differences in relation to competition levels may give coaches a better working knowledge of the studied groups of athletes.

For other variables, some values are better for players of FC Feronikeli, some for players of OFC Titograd or 
FC Siroki Brijeg, although, insignificantly for statistics. This indicates that these players have very similar anthropometric parameters and body composition, which is again, not surprising, considering that these three clubs are among the best in their countries. The concentration of the best soccer players in these three-member states of the southern region of the Balkan Peninsula is in these 3 clubs. The assumption is that the mean values of the analyzed variables in all of them should be the model values for the soccer players of other clubs.

Compered to all the participants in the 2018 World Soccer Championship, the average height of the players in these three countries is enough for their age. An official statistical data showed the average height in Rusia 181.70 centimeters, while in Croatia league $(183.60 \mathrm{~cm})$, Germany $(183.5 \mathrm{~cm})$, Denmark $(183.5 \mathrm{~cm})$, Poland (183 $\mathrm{cm})$.

\section{Conclusion}

The values obtained in this research can be useful for coaches of other clubs for making a comparations and formulate their training in a way that enables reduction of those parameters that are not good, and raise those that are good to a higher level. That will surely make their soccer players even better and more successful. Also, soccer clubs in states of the southern region of the Balkan Peninsula should turn to other researches. They should check the functional-motoric status, psychological preparation as well as tactical training of their players and analyze whether there is a room for their improvement.

\section{Conflicts of interest}

The authors declare no conflict of interest.

\section{References}

1. Akbari H, Sahebozamani M, Daneshjoo A, Amiri-Khorasani M. Effect of the FIFA 11+ programme on vertical jump performance in elite male youth soccer players. Montenegrin Journal of Sports Science and Medicine. 2018; 7(2):17-22. https://doi.org/10.26773/mjssm.180903

2. Gardasevic J, Bjelica D, Corluka M, Vasiljevic I. Elite football players from Bosnia and Herzegovina and Kosovo and their body composition. Sport Mont. 2019; 17(2):75-79. https://doi.org/10.26773/smj.190613

3. Corluka, M., Bjelica, D., Vasiljevic, I., Bubanja, M., Georgiev, G., \& Zeljko, I. (2018). Differences in the morphological characteristics and body composition of football players of hsc zrinjski mostar and fc siroki brijeg in bosnia and herzegovina. Sport Mont, 16(2), 77-81. https://doi.org/10.26773/smj.180614

4. Amani AR, Sadeghi H, Afsharnezhad T. Interval training with blood flow restriction on aerobic performance among young soccer players at transition phase. Montenegrin Journal of Sports Science and Medicine. 2018; 7(2):5-10. https://doi.org/10.26773/mjssm.180901

5. Triki M, Rebai H, Abroug T, Masmoudi K, Fellmann N, Zouari M, Tabka Z. Comparative study of body composition and anaerobic performance between soccer and judo groups. Science and Sports. 2012; 27(5):293-9. https://doi.org/10.1016/j.scispo.2011.07.004

6. Carter JEL, Heath BH. Somatotyping-Development and application. Cambridge, United Kingdom: Cambridge University Press, 1990.

7. Carvajal W, Betancourt H, León S, Deturnel Y, Martínez M, Echevarría I, Eugenia Castillo $M$, Serviat N. Kinanthropometric Profile of Cuban Women Olympic Volleyball Champions. MEDICC Review. 2012; 14(2):16-22. https://doi.org/10.1590/S1555-79602012000200006

8. Ramadan J, Byrd R. Physical characteristics of elite soccer players. Journal of Sports Medicine and Physical Fitness. 1987; 27:424-428.
9. Green S. Anthropometric and physiological characteristics of south Australian soccer players. Australian Journal of Science and Medicine in Sport. 1992; 24:3-7.

10.Rico-Sanz J. Body composition and nutritional assessments in soccer. International Journal of Sport Nutrition. 1998; 8:113-123. https://doi.org/10.1123/ijsn.8.2.113

11.Rienzi E, Drust B, Reilly T, Carter JEL, Martin A. Investigation of anthropometric and work-rate profiles of elite South American international soccer players. J Sports Med Phys Fitness. 2000; 40(2):162-169.

12.Kemi OJ, Hoff J, Engen LC, Wisloff U. Soccer specific testing of maximal oxygen uptake. The Journal of Sports Medicine and Physical Fitness. 2003; 43(2):139-44.

13. Sutton 1, Scott M, Wallace J, Reilly T. Body composition of English Premier League soccer players: Influence of playing position, international status, and ethnicity. Journal of Sports Sciences. 2009; 27(10):1019-1026. https://doi.org/10.1080/02640410903030305

14.Tahara Y, Moji K, Tsunawake N, Fukuda R, Nakayama M, Nakagaichi M, Komine T, Kusano Y, Aoyagi K. Physique, body composition and maximum oxygen consumption of selected soccer players of Kunimi High School, Nagasaki, Japan. J Physiol Anthropol. 2006; 25:291-297.

15. Masocha V, Katanha A. Anthropometry and somatotype characteristics of male provincial youth league soccer players in Zimbabwe according to playing positions. Int $J$ Sci Res. 2014; 3:554-557.

16. Silvestre R, Kraemer WJ, West C, Judelson DA, Spiering BA, Vingren JL, Hatfield DL, Anderson JM, Maresh CM. Body Composition and Physical Performance during a National CollegiateAthleticAssociationDivisionIMen's SoccerSeason. J. Strength and Conditioning Research. 2006; 20(4):962-70. https://doi.org/10.1519/00124278-200611000-00038 


\section{Information about the authors:}

Gardasevic J.; (Corresponding author); https://orcid.org/0000-0002-1387-1521; jovan@ucg.ac.me; University of Montenegro; Cetinjski put 2, 81000, Podgorica, Montenegro.

Bjelica D.; https://orcid.org/0000-0001-5272-528X; dbjelica@ucg.ac.me; University of Montenegro; Cetinjski put 2, 81000, Niksic, Montenegro.

Vasiljevic I.; https://orcid.org/0000-0001-9463-2532; vasiljevic.ivan301@gmail.com; University of Montenegro; Cetinjski put 2,81000, Niksic, Montenegro.

Cite this article as:

Gardasevic J, Bjelica D, Vasiljevic I. Differences in anthropometric characteristics between young soccer players (U19) members of the best soccer clubs in Montenegro, Bosnia and Herzegovina, and Kosovo. Pedagogy of physical culture and sports, 2020;24(1):21-25. https://doi.org/10.15561/18189172.2020.0103

This is an Open Access article distributed under the terms of the Creative Commons Attribution License, which permits unrestricted use, distribution, and reproduction in any medium, provided the original work is properly cited (http://creativecommons.org/licenses/by/4.0/deed.en).

Received: 02.10.2019

Accepted: 25.10.2019; Published: 10.11.2019 